\title{
AVALIAÇÃO, IDENTIDADES E GÊNERO: ANÁLISE DE NARRATIVAS DE VIOLÊNCIA DOMÉSTICA EM UMA INTERAÇÃO ENTRE MULHERES
}

\author{
Adriana Nogueira A. NÓBREGA* \\ Adriana Rodrigues de ABREU**
}

- RESUMO: Esta pesquisa investiga as relações entre os usos avaliativos da linguagem e as (re)construções de identidades de gênero, a partir da análise de narrativas orais de experiências pessoais sobre violências domésticas, sofridas por mulheres em seus ambientes familiares, relatadas em uma interação acadêmica. Inserida na área da Linguística Aplicada Contemporânea, e com base em um arcabouço teórico-metodológico crítico, o estudo analisa como as participantes estruturam, negociam e (re)constroem identidades ao longo das narrativas, observando, sobretudo, como lidam com questões de gênero ideologicamente impostas pela sociedade. Para alcançar os objetivos propostos, a visão de gênero como ato performativo, desempenhado por meio do uso da linguagem, foi alinhada à abordagem interacional de narrativa e à concepção socioconstrucionista de identidades. A metodologia de pesquisa qualitativa orientou a análise da prática narrativa, centrada nos elementos avaliativos que constituem o discurso. Os resultados sugerem que tanto o gênero como as identidades são produtos das performances locais de indivíduos sócio-historicamente situados em atividades discursivas diversas.

- PALAVRAS-CHAVE: narrativas orais de experiências pessoais; violência doméstica; identidades de gênero; avaliação.

\section{Considerações iniciais}

Neste artigo, analisamos as relações entre os usos avaliativos da linguagem e as (re)construções de identidades de gênero, a partir de um arcabouço teóricometodológico crítico voltado para a inter-relação entre gênero, identidades e avaliação em narrativas orais de experiências pessoais. A pesquisa centra-se na área da Linguística Aplicada Contemporânea, campo de investigação indisciplinar e mestiço que busca criar inteligibilidades sobre os usos da linguagem em contextos sociais específicos

Pontifícia Universidade Católica do Rio de Janeiro (PUC-Rio). Rio de Janeiro - RJ - Brasil. adriana.nnobrega@gmail. com. ORCID: 0000-0002-0194-0120.

** Rede Municipal do Rio de Janeiro. Secretaria Municipal de Educação. Rio de Janeiro - RJ - Brasil. adrianarodriguess@ yahoo.com.br. ORCID: 0000-0003-2359-6372. 
(MOITA LOPES, 2006; PENNYCOOK, 2006). A Linguística Aplicada Contemporânea vai em direção a um "projeto epistemológico com implicações sobre a vida social" (MOITA LOPES, 2006, p. 91), sendo uma área continuamente crítica e auto-reflexiva (PENNYCOOK, 2004, 2006) e que se preocupa com questões relacionadas à vida sociocultural, política e histórica (MOITA LOPES, 2006).

Alicerçada nos princípios da Linguística Aplicada Contemporânea, a concepção teórica aqui adotada segue uma perspectiva não essencialista de identidades e argumenta que, em vez de uma realidade dada, pronta e acabada, as identidades emergem de, e são construídas em, contextos socioculturais particulares e apenas podem ser compreendidas como efeitos de performances corporais e linguísticas. Partimos, portanto, de uma perspectiva crítica de linguagem (FAIRCLOUGH, 2003; PENNYCOOK, 2004), entendendo o discurso como parte fundadora e constitutiva da prática social, um modo de ação sobre o mundo e a sociedade (FAIRCLOUGH, 2003). Analisar criticamente a prática discursiva é levar em conta "as premissas de que o discurso é estruturado pela dominação; que cada discurso é historicamente produzido e interpretado, isto é, está situado no tempo e no espaço; e que as estruturas de dominação são legitimadas pelas ideologias dos grupos que detêm o poder ${ }^{1}$." (WODAK, 2004, p. 226).

Seguindo tais pressupostos, analisamos uma interação ocorrida entre mulheres participantes de um grupo de pesquisa, vinculado a uma universidade do Rio de Janeiro. Nosso foco recai sobre a narração de histórias de violências domésticas sofridas pelas participantes (sejam estas físicas, psicológicas, materiais, dentre outras), especialmente sobre a investigação dos elementos discursivos avaliativos que contribuem para as (re)construções das identidades de gênero de $\mathrm{Carina}^{2}$, narradora principal de uma das histórias relatadas na interação ${ }^{3}$, quando ela conta a agressão física que sofreu em seu ambiente familiar.

Nesse sentido, para estudarmos a fala em interação do grupo de mulheres em questão, recorremos à perspectiva de gênero como ato performativo, desempenhado por meio do uso da linguagem (BUTLER, 2003) e não como algo com o que se nasce. Alinhadas a esta visão de gênero como ato discursivo performativo, nos fundamentamos na abordagem social de identidades, entendendo-as como múltiplas, fluidas e fragmentadas (MOITA LOPES, 2003; BUCHOLTZ, 1990; SAWIM, 1990), assim como construídas de forma colaborativa em práticas discursivas localizadas, únicas e específicas a cada interação social.

Inspiradas por paradigmas teóricos e metodológicos socioconstrutivistas, e uma vez que consideramos as narrativas como locus para a reconstrução de experiências pessoais, nos baseamos na perspectiva interacional (DE FINA, 2008; BASTOS, 2004; MOITA

\footnotetext{
As traduções apresentadas neste artigo foram realizadas de forma livre pelas autoras.

Nome fictício.

Por questões de limitação na extensão deste artigo, trazemos, para análise e interpretação dos dados, apenas uma das narrativas produzidas na interação entre as participantes. Acreditamos, contudo, não ser este fato uma impossibilidade de acesso ao teor das outras histórias relatadas, que se apresentaram bastante semelhantes, no que tange às (re) construções de identidades de gênero.
} 
LOPES, 2001) para as análises da narrativa selecionada, pois nos atemos aos aspectos interacionais e interpessoais que a compõe. Os momentos discursivos avaliativos direcionam o nosso olhar analítico, uma vez que são "a razão de ser da narrativa" (LABOV, 1972, p.366, tradução nossa) e, em consonância com Linde (1997, p. 152, tradução nossa), consideramos como avaliação "qualquer instanciação produzida pelo falante que tenha sentido social ou que indique o valor de uma pessoa, coisa, evento ou relacionamento", compreendendo a avaliação como um fator intrinsecamente relacionado à dimensão moral da linguagem.

Notamos, assim, a importância da avaliação para a construção de sentidos, visto que ela pode ser considerada "uma das funções mais básicas e importantes da linguagem e vale a pena investigá-la em profundidade", uma vez que "encontrar um texto ou mesmo uma frase sem nenhum traço de avaliação é uma tarefa muito desafiadora, se não impossível ${ }^{6 "}$ " (ALBA-JUEZ; THOMPSON, 2014, p. 5, tradução nossa). Portanto, para a análise da prática discursiva avaliativa, tomamos o sistema de avaliatividade (MARTIN, 2001; MARTIN; WHITE, 2005), integrante da abordagem sociossemiótica de linguagem proposta pela Linguística Sistêmico-Funcional (HALLIDAY, 1994; MARTIN; ROSE, 2007), como ferramenta para a análise das escolhas discursivas avaliativas, principalmente as ligadas às dimensões afetiva e moral da linguagem.

O paradigma qualitativo e interpretativo de pesquisa (DENZIN; LINCOLN, 2006) orienta o nosso caminho analítico e ressaltamos que, ao investigar as (re)construções de identidades de gênero em narrativas orais de experiências pessoais, o presente artigo tem por objetivo analisar como as participantes deste estudo estruturam, negociam e (re)constroem suas identidades ao longo da história contada por Carina. Com isso, acreditamos ser possível observar como as interlocutoras lidam com as questões de gênero em uma sociedade majoritariamente hegemônica e ideologicamente patriarcal, que impõe determinadas maneiras de ser aprioristicamente.

\section{Gênero, identidades e avaliação em narrativas}

Os estudos sobre gênero vêm passando por modificações e reformulações nas Ciências Sociais e nas Ciências Humanas. Inicialmente, podemos citar as contribuições da antropóloga Margareth Mead (1979) que, em sua obra Sexo e temperamento em três sociedades primitivas, publicada em sua primeira edição em 1934, já buscava se distanciar de visões biologizantes e naturalistas que abordavam o comportamento de homens e mulheres como consequência direta do sexo biológico. Embora não tenha utilizado a conceituação de gênero, sua ideia era a de que haveria um sexo natural

\footnotetext{
4 Original: "the raison d'être of the narrative" (LABOV, 1972, p.366).

5 Original: "any instantiation produced by the speaker that has social meaning or that indicates the value of a person, thing, event or relationship" (LINDE, 1997, p. 152).

6 Original: "finding a text or even a sentence without any trace of evaluation is a very challenging task, if not impossible" (ALBA-JUEZ; THOMPSON, 2014, p. 5).
} 
ou pré-discursivo, de um lado, e um gênero culturalmente construído, do outro. $\mathrm{O}$ entendimento de que o gênero seria a expressão do social, enquanto o sexo da ordem do natural, foi questionado, uma vez que é impossível estabelecer uma natureza sexuada anterior ao âmbito social. Podemos dizer, então, que a definição de sexo feminino e de sexo masculino não existe como uma verdade absoluta, mas como um conceito construído sociohistoricamente.

Estudos posteriores, como os de Michel Foucault (1977), indicam a importância de atentarmos para a ordem discursiva da noção de sexo, assim como para o fato de que a identidade de gênero é constituída por meio de nossas performances discursivas ${ }^{7}$. Ainda neste horizonte, em seus estudos, Judith Butler (2003) afirma que não há diferenças sexuais entre si. Contudo, a existência de uma matriz heteronormativa supõe uma coerência entre sexo e gênero e, levando-se isto em conta, a performance do gênero masculino implica necessariamente uma associação ao sexo masculino, assim como o mesmo ocorre para o sexo feminino. A autora aponta que "mesmo que sexos pareçam não problematicamente binários em sua morfologia e constituição (...), não há razão para supor que gêneros também devam permanecer em número de dois" (BUTLER, 2003, p. 24).

Butler $(2003,2008)$ também enfatiza que o gênero é produzido em práticas discursivas diárias, que se manifestam nas performances de homens e de mulheres, com base em padrões reguladores do que é ser homem ou ser mulher dentro de uma determinada sociedade. Tal concepção de construção do gênero está vinculada à capacidade da linguagem em realizar coisas no mundo. Para a autora (BUTLER, 2008), a possibilidade de os gêneros se constituírem pela linguagem está pautada em uma visão performativa desta. De acordo com Cameron (2010, p. 131), "Butler afirma que 'feminino' e 'masculino' não são características que nós possuímos, mas efeitos que produzimos por meio das coisas específicas que fazemos". Nesse sentido, os atos discursivos são performativos, pois "a essência ou a identidade que pretendem expressar são fabricações manufaturadas e sustentadas por signos corpóreos e outros meios discursivos" (BUTLER, 2003, p. 194).

Desse modo, podemos dizer que as identidades de gênero não são pré-formadas, mas são, ao contrário, e de acordo com Pennycook (2004), performadas em práticas discursivas contextualizadas. Esta visão de identidades como ato social já se fazia presente nos estudos de Bucholtz (1990), para quem a identidade é uma construção discursiva, uma produção local e não uma categoria estática. A autora, além de entender as identidades como performativas, também ressalta que as mulheres são usuárias ativas da língua, não sendo apenas vistas como vítimas, mas como agentes de reflexão, ainda

\footnotetext{
Tomamos por base o conceito de performance proposto por Goffman, que o define como "toda atividade de um determinado participante, em dada ocasião, que sirva para influenciar, de algum modo, qualquer um dos outros participantes" (GOFFMAN, [1959] 2014, p.23). Ainda, para Butler (1990), ao discutirmos sobre gênero, devemos pensar tanto no aspecto de performance quanto de performatividade. Para a autora, performance relaciona-se ao nosso atuar em determinado papel de gênero, no sentido do display público e da atuação teatral. A performatividade, que liga-se ao fazer de um determinado gênero, é um construto social, construído pelas interações discursivas, realizadas em contextos sociais específicos (BORGES, 2016).
} 
que ocorra uma opressão a priori. Conforme observaremos nos dados deste estudo, a narradora se coloca em muitos momentos como agente de reflexão, mesmo que esteja cercada por ideologias patriarcais hegemônicas, pelas quais a mulher é oprimida (BEAUVOIR, 1967). Com isso, entendemos que as identidades são, muitas vezes, (re) construídas como um possível mecanismo linguístico de autoproteção.

Na mesma linha de pensamento, Cameron (2001) afirma que somos construídos a partir do que falamos e, ao falarmos, utilizamos discursos que estão presentes em uma cadeia discursiva ideológica, disponível aos falantes. Sendo assim, nossos discursos podem ecoar (repetir, reiterar) normas de heteronormatividade, nos impelindo, muitas vezes, a posições de sujeitos com as quais necessariamente não nos identificamos. Podemos dizer que são forças ideológicas presentes nos discursos sociais, em que o discurso, sobretudo o hegemônico, sobressai-se em detrimento de outras posições discursivas pertencentes a grupos que não detém o poder.

A perspectiva de identidade como ato performativo, como uma performance, nos leva à sua natureza discursiva (SAWIN, 1990; BUCHOLTZ; HALL, 2003, 2005), o que nos faz estabelecer conexões teóricas com os estudos socioconstrucionistas de identidades. Compreendidas como múltiplas, fluidas, fragmentadas e contraditórias (MOITA LOPES, 2002, 2003), as identidades têm suas origens em processos históricos e sociais e, desse modo, podemos dizer que práticas discursivas, mundo social e construções identitárias encontram-se amalgamados. Moita Lopes (2003) aponta que as identidades são um construto de natureza social, não dizendo respeito à natureza da pessoa e, como afirma o autor, as identidades são construídas no discurso, sendo o indivíduo membro de muitos discursos, que representam cada uma de suas identidades. É possível reforçar, ainda, que as identidades possuem uma estreita relação de dependência com as diferenças, já que, de acordo com Silva (2000 apud RESENDE; RAMALHO, 2006, p. 76), "a afirmação da identidade é parte de uma cadeia de negações, de diferenças (...). Identidade e diferença são, então, conceitos mutuamente determinados".

Uma vez que nos voltamos para a análise das identidades de gênero discursivamente performadas em narrativas orais de experiências pessoais, também adotamos uma concepção interacional de narrativa. Em consonância com a perspectiva socioconstrucionista de narrativa (BASTOS, 2005, 2008; MOITA LOPES, 2001), afirmamos a impossibilidade de investigarmos a produção discursiva narrativa fora de seus contextos histórico, social e cultural de produção. Moita Lopes aponta que investigar a prática narrativa nos possibilita analisar a (re)construção de identidades, e destaca "o papel que as narrativas desempenham na construção de identidades sociais nas práticas narrativas onde as pessoas relatam a vida social e, em tal engajamento discursivo, se constroem e constroem os outros" (MOITA LOPES, 2001, p. 63). Sendo assim, a performance narrativa não ocorre em campo neutro e isento de valores e crenças, mas, de forma diferente, ocorre em meio a embates discursivos e ideológicos por natureza (ABREU, 2018). No momento em que narramos fatos, há um investimento discursivo na produção e na manutenção das identidades de uma coletividade, conforme observaremos nas análises deste estudo. A partir dessa visão mais ampla, "a narrativa 
passa a ser vista como uma construção social" (BASTOS, 2004, p. 121) e, como sugerem Nóbrega e Magalhães (2012), é a partir de nossas narrativas que dizemos quem somos, o que desejamos ou acreditamos, sempre nos reconstruindo a cada relato narrativo.

Como visto, consideramos extremamente relevante a influência de fatores sociais, culturais e interacionais na estruturação das narrativas, o que nos faz entendê-la como "uma forma de organização básica da experiência humana, a partir da qual se pode estudar a vida social em geral (...), contar estórias é [desse modo] uma prática social, uma atividade histórica e culturalmente situada" (BASTOS, 2004, p. 119). Logo, as narrativas são (co)construídas funcionalmente nas interações, sendo vistas como uma prática situada, isto é, que são construídas ao longo da interação social (DE FINA; GEORGAKOPOULOU, 2008).

A ideia de narrativa como práxis performativa em que, interacionalmente, narrador e audiência (co)constroem sentidos e valores (LINDE, 1997), nos remete à questão da avaliação em narrativas. Em seus estudos seminais, Labov e Waletzky (1967) e Labov (1972), propõem que a função da avaliação ${ }^{8}$ em narrativas é informar sobre a carga dramática e emocional do evento relatado, assim como dos participantes da interação narrativa, sendo, para os autores, "a razão de ser da narrativa” ou, ainda, como sugere Reissman (1993, p. 20), a "alma da narrativa".

Buscando trazer uma visão mais ampla da prática discursiva avaliativa, uma vez que esta é um dos pontos centrais de nossas análises, nos alinhamos a Thompson e Hunston (2006), que propõem as seguintes funções para a avaliação no discurso:

(i) expressar as opiniões de falantes e de escritores, proporcionando o entendimento do sistema de valores do falante (ou escritor) e de sua comunidade;

(ii) construir e manter relações entre falante e ouvinte (ou escritor e leitor) e

(iii) organizar o discurso (THOMPSON; HUNSTON, 2000). Com tal proposta, observamos que há um distanciamento de uma avaliação centrada no "eu”, que passa a ser concebida como um recurso interacional, onde falante (ou escritor) e ouvinte (ou leitor) constroem colaborativamente suas atitudes diante dos fatos avaliados.

Os estudos de Thompson e Hunston (2000, 2006) são ampliados por Alba-Juez e Thompson (2014), que trazem os elementos contextuais, de forma mais preeminente, para o centro de sua perspectiva sobre a avaliação em práticas discursivas. O contexto passa a ter papel mais central para a análise da linguagem avaliativa e os contextos cultural e situacional são investigados em uma relação dialética com o discurso avaliativo. As interações são, assim, interpretadas considerando-se elementos macro e micro sociais, ou seja, tudo o que estiver circundando o falante (ou escritor) e ouvinte (ou leitor) em seu uso da linguagem (ALBA-JUEZ; THOMPSON, 2014).

Nossa discussão sobre contexto se fundamenta na proposta de Michael Halliday, descrita em sua abordagem funcionalista de linguagem como elemento sociossemiótico. Para o autor e seus seguidores (EGGINS, 2004; MARTIN; ROSE, 2007; GOUVEIA,

Labov e Waletzky (1967) e Labov (1972) sugerem uma estrutura básica da narrativa, que é composta por seis elementos: resumo, orientação, ação complicadora, avaliação, resolução e coda. Para o presente estudo, entretanto, apenas o elemento avaliação será investigado. 
2009, dentre outros), a linguagem deve sempre ser analisada em seu uso, enquanto realizamos nossas atividades cotidianas. Com base em tal pressuposto, o autor propõe que há dois tipos de contextos que devem ser investigados quando em momento de análise de discursos específicos: o contexto de cultura e o contexto de situação, sendo o segundo parte integrante do primeiro. O contexto de cultura relaciona-se ao conjunto de procedimentos que as culturas institucionalizam como uma forma de atingir seus objetivos, isto é, refere-se aos rituais, às formas de polidez, às maneiras de interagir que criam significados em diferentes culturas (EGGINS, 2004). Inserido no contexto de cultura, o contexto de situação, por sua vez, é o ambiente do texto (HALLIDAY; HASAN, 1989), o local mais imediato onde o texto se desenvolve e que ilustra a natureza da ação, seus participantes e o papel que a linguagem está desempenhando em dada situação interacional.

Os contextos de situação e de cultura, portanto, permeiam todo o sistema linguístico e, na perspectiva hallidayana, são concretizados nos estratos semântico discursivo, lexicogramatical e grafo-fonológico (HALLIDAY; MATTHIESSEN, 2014). A importância do contexto e sua realização em tais estratos é central para as análises que trazemos neste artigo, uma vez que as desenvolvemos a partir de uma concepção de avaliação como elemento contextual, interacional e discursivo. Desse modo, para observarmos as avaliações presentes no discurso narrativo da participante Carina, recorremos ao sistema de avaliatividade (MARTIN, 2001; MARTIN; WHITE, 2005), componente da teoria sistêmico-funcional.

O sistema de avaliatividade, conforme proposto por Martin e White (2005), lida com a linguagem da avaliação e pode ser definido como uma perspectiva de análise textual, situando-se no campo da avaliação das atividades interpessoais, no nível da semântica do discurso. Tais atividades são dinamicamente estabelecidas ao longo do texto, isto é, os significados são criados no discurso durante as interações sociais, de acordo com aspectos contextuais específicos a cada interação (MARTIN; ROSE, 2007; NÓBREGA, 2009; WHITE, 2021).

Três subsistemas, ou domínios, compõem, de forma interconectada, o sistema de avaliatividade: atitude, engajamento e gradação, criando cada um deles uma região de significados. Para a análise do discurso avaliativo, e de acordo com cada domínio, podemos sugerir as seguintes perguntas: qual a natureza da avaliação? (atitude); de onde vem a avaliação e que vozes nela se encontram? (engajamento); e, por último, o quão forte é a avaliação? (gradação) (NÓBREGA, 2009). Para a observação das (re) construções das identidades de gênero de Carina, e por questões de recorte e seleção dos dados, embasaremos nossas análises no domínio da atitude e em seus componentes afeto, julgamento e apreciação, que, respectivamente, se voltam à linguagem avaliativa da emoção, da ética e da estética (MARTIN; WHITE, 2005). Os subsistemas do afeto, do julgamento e da apreciação possuem características particulares e referem-se a diferentes aspectos. Contudo, o afeto permeia os domínios do julgamento e da gradação, interligando-os, uma vez que estes também possuem componentes do afeto.

Martin e White (2005) propõem as seguintes categorias para cada domínio avaliativo: 
(i) no âmbito do afeto, referem-se às manifestações discursivas das emoções de (in)felicidade, (in)satisfação e (in)segurança, com foco no avaliador, de forma autoral ou não-autoral;

(ii) no âmbito do julgamento, relacionam-se às instanciações de julgamento de comportamento certo vs errado, seja de estima social ou de sanção social, e voltam-se ao avaliado e

(iii) no âmbito da apreciação, dirigem-se às avaliações de pessoas, objetos ou entidades, sendo realizadas por reação, composição ou valor social. ${ }^{9}$

Todos os três domínios podem se realizar de forma positiva ou negativa, explícita (quando o sentido das palavras é diretamente construído no texto) ou implícita (quando a avaliação é inferida a partir de significados criados pela participação de ouvintes/ leitores, ao interpretar o que foi dito/escrito pelo falante/escritor).

Com o objetivo de analisarmos os elementos discursivos avaliativos que contribuem para as (re)construções de identidades de gênero de Carina, temos especial interesse pelas avaliações implícitas, que se realizam predominantemente no estrato semântico ${ }^{10}$ da linguagem e que se tornam, assim, fortemente dependentes de fatores contextuais. Seguimos a abordagem de avaliação como um recurso semântico do discurso, que se concentra no "significado além da oração" "(MARTIN; WHITE, 2005, p. 9, tradução nossa). Corroborando tal posicionamento, Macken-Horarik e Isaac (2014, p. 68, tradução nossa) sugerem que "em contraste com os conceitos lexicais de avaliação, o alcance da avaliação em todo o texto permite que os analistas rastreiem não apenas expressões explícitas de atitude, mas também as relações que eles contraem com formas implícitas de avaliação e seu significado cumulativo ${ }^{12}$ ".

\section{Caminhos metodológicos e contextualização dos dados}

Desenvolvido de acordo com os pressupostos da Linguística Aplicada Contemporânea (MOITA LOPES, 2006; PENNYCOOK, 2006), este estudo alinha-se à metodologia de pesquisa qualitativa (DENZIN; LINCOLN, 2006) para a análise da relação entre avaliação em narrativas e (re)construção de identidades de gênero, com foco em uma interação entre membras de um grupo de pesquisa, vinculado a um programa de pósgraduação em Estudos da Linguagem, localizado no Rio de Janeiro. As correlações

\footnotetext{
9 A proposta teórico-analítica do sistema de avaliatividade é bastante ampla e, por questões de espaço e de escopo neste artigo, trazemos apenas uma breve introdução de suas categorias analíticas. Para um maior detalhamento, sugerimos a leitura de Martin e White (2005), White (2021) e Vian Jr (2010).

10 As avaliações materializam-se na prosódia do discurso e são realizadas em todos os estratos da linguagem, a saber: semântico, lexicogramatical e grafo-fonológico (ALBA-JUEZ; THOMPSON, 2014; HALLIDAY, 1994; MARTIN; WHITE, 2005).

11 Original: "meaning beyond the clause" (MARTIN; WHITE, 2005, p. 9).

12 Original: "in contrast to lexical concepts of evaluation, the scope of evaluation throughout the text allows analysts to track not only explicit expressions of attitude, but also the relationships they enter into with implicit forms of evaluation and their cumulative meaning" (MACKEN-HORARIK; ISAAC, 2014, p. 68).
} 
que aqui propomos surgiram após o momento da escuta dos dados, que foram gerados de forma praticamente espontânea, uma vez que a iniciativa de gravação da interação surgiu da coordenadora do grupo, ao perceber a riqueza dos relatos feitos ao longo da reunião e sua consequente contribuição para as discussões realizadas no próprio grupo de pesquisa. A gravação da interação ocorreu apenas após todas as participantes terem concedido permissão para o registro em áudio e ressaltamos que a presente pesquisa está de acordo com a Resolução n. 510, de 07 de abril de 2016, estando alicerçada "no respeito pela dignidade humana e na proteção devida aos participantes das pesquisas científicas envolvendo seres humanos"13.

A interação em tela ocorreu em uma das reuniões quinzenais do grupo de pesquisa, quando estavam reunidas, em uma sala da universidade, sete participantes do grupo e uma professora convidada. Como em outros encontros, as atividades realizadas na ocasião foram voltadas à discussão de textos teóricos, ao relato de pesquisas em desenvolvimento e/ou concluídas, dentre outras atividades relacionadas às investigações conduzidas pela professora coordenadora, por suas/seus alunas/os ou ex-alunas/os de pós-graduação, ou por eventuais convidadas/os.

No total, participaram da reunião oito mulheres, todas elas envolvidas em pesquisas acadêmicas. Na ocasião da gravação, uma participante era aluna do curso de Especialização em Língua Inglesa, três cursavam o Mestrado e duas o Doutorado, enquanto as outras duas eram professoras universitárias em instituições distintas. A coordenadora do grupo era, na época, a orientadora das alunas de mestrado, doutorado e especialização. Com o intuito de preservar a identidade das participantes, com a exceção da identificação das autoras deste artigo, todos os nomes foram substituídos por outros fictícios: Aline (estudante de especialização); Heloá, Noemi e Carina (mestrandas); Adriana A. e Monique (doutorandas); Adriana N. (professora universitária e coordenadora do grupo) e Luana (professora universitária convidada). É importante destacar que a narradora principal é Carina e que nem todas as participantes falam nos fragmentos aqui transcritos.

Como dito, o encontro analisado contou com a participação da professora convidada Luana, ativista feminista, cujo interesse centrava-se nas discussões realizadas pelo grupo e em seu foco teórico-analítico da Linguística Sistêmico-Funcional (HALLIDAY; MATTHIESSEN, 2014). Para a data da reunião em questão, a coordenadora Adriana N. sugeriu a leitura de dois textos de autoria da pesquisadora convidada, que versam sobre seus estudos acerca da Lei Maria da Penha ${ }^{14}$. Durante a reunião, houve certa "catarse", uma vez que muitas narrativas com temas de violência contra a mulher surgiram, com foco na (re)construção das identidades de gênero das participantes. Acreditamos, assim, que as narrativas que investigamos são espontâneas e que o tópico conversacional foi

13 Disponível em: http://conselho.saude.gov.br/resolucoes/2016/Reso510.pdf. Acesso em: 26 out. 2021.

14 A Lei Maria da Penha (Lei n $\left.{ }^{\circ} 11.340\right)$ "cria mecanismos para coibir e prevenir a violência doméstica e familiar contra a mulher" (BRASIL, 2006). Sancionada pelo presidente Luiz Inácio Lula da Silva, em 7 de agosto de 2006, a lei foi batizada em homenagem a Maria da Penha, uma ativista dos direitos das mulheres. Maria da Penha ficou paraplégica após sofrer muitas agressões violentas do marido. 
motivado pelos textos de Luana e pelo próprio contexto de vida em que as participantes estavam inseridas.

Para este artigo, recortamos um fragmento de uma gravação mais extensa e selecionamos as partes em que mais emergem questões de (re)construção das identidades de gênero. Na análise dos dados, trazemos quatro fragmentos que foram representativos para as nossas interpretações. A gravação total teve a duração de 1 hora, 36 minutos e 42 segundos e, para os propósitos desta discussão, foram transcritos 5 minutos e 3 segundos. Os dados foram transcritos de acordo com as convenções adaptadas de Sacks, Schegloff e Jefferson (1974), com incorporações de Loder e Jung (2009) ${ }^{15}$.

\section{Práticas narrativas e performances de identidades de gênero}

Tendo em vista os objetivos que indicamos anteriormente, nesta seção, trazemos a análise dos dados. No início da gravação, a narradora Carina faz uma contextualização de sua narrativa, apresentando personagens, lugares, tempo e situação em que ocorreu o evento reportado: uma briga física entre ela e seu irmão. Em nossas análises, daremos destaque à parte em que Carina reporta a reação dos participantes envolvidos (sua avó, sua mãe, seu irmão e ela própria), além de sua posição sobre o acontecimento por ela vivido. Nesta parte inicial, encontramos o ponto central da narrativa, que é a violência física de seu irmão, fato que nos possibilita olhar para a (re)construção das identidades de gênero, tanto das participantes do grupo de pesquisa, presentes no momento do relato, quanto para as identidades projetadas aos participantes do evento narrado, conforme observamos no excerto 1 , a seguir.

\section{Excerto 1}

01 Carina aí eu consegui abrir e ele desceu pra a casa da minha avó primeiro que eu (...) [e quando eu cheguei] lá:: [na casa da minha avó]

03 Luana

[opra fazer fuxico $\left.{ }^{\circ}\right]$

04 Adriana N.

[pra fazer fuxico [hhh]

05 Luana

$[\mathrm{hhhh}]=$

06 Carina

=NÃO e ele desceu pra a casa da minha avó como se nada tivesse acontecido e EU desci super nervosa assim o meu corpo tava tremendo to::do quando eu cheguei na casa da minha avó:: (.) tava minha mãe, minha avó e ele (.) e parecia assim uma:: barreira como se:: (...) é::: EU

09 fosse a vilã da história (.) o circo assim já estava ARMADO e eu cheguei assim e eu falei assim "mãe você não sabe o que aconteceu个" e ela "eu já estou sabendo o que aconteceu” e ela falou com um tom meio áspero como se tipo assim=

13 Adriana N. =a culpa fosse ser sua $\uparrow$

15 As convenções de transcrição encontram-se no anexo deste trabalho. 
No fragmento acima, Carina narra o momento em que seu irmão, após a briga, segue para a casa da sua avó para encontrar com sua mãe (linhas 01-02), o que representa uma contextualização do evento. As participantes Luana e Adriana N. avaliam a postura do irmão de Carina por meio de um julgamento negativo de estima social, contribuindo para a construção avaliativa da narrativa e, ao mesmo tempo, para a projeção da construção de identidade do irmão, visto pelas participantes como fuxiqueiro (linhas 03 e 04). $\mathrm{O}$ uso de "fuxico" acentua o teor negativo do comportamento do irmão da narradora e Luana e Adriana $\mathrm{N}$. entendem sua atitude como uma possível fofoca ou intriga. $\mathrm{O}$ fato de as professoras terem feito tal afirmação com risos, nos remete a uma possível ironia das participantes e ao aumento da gradação na avaliação de ambas, como forma de uma avaliação negativa implícita. Cabe lembrar que o tema geral da reunião relacionava-se a situações de violências sofridas por mulheres, em um sociedade heteronormativa, com ênfase no favorecimento a posições de homens nas práticas sociais.

Além disso, Carina faz uma oposição entre a sua postura ("eu desci super nervosa assim o meu corpo tava tremendo to::do", na linha 07) e a postura do seu irmão ("ele desceu para a casa da minha avó como se nada tivesse acontecido", na linha 06). Nas linhas 06-07, já podemos perceber, portanto, como ela se constrói identitariamente em oposição a ele, que age como se nada tivesse acontecido. Como dito em momento anterior, a construção das identidades é parte de uma cadeia de negações e de diferenças (SILVA, 2000 apud RESENDE; RAMALHO, 2006). Isto é corroborado logo adiante, nas linhas 09-12, quando Carina menciona ser considerada a vilã da história, o que podemos inferir ser dito em oposição ao "herói", que seria seu irmão. Nesta avaliação de afeto negativo de insatisfação, a narradora ainda menciona o fato de "o circo já está armado" (dito em voz alta, denotando alta gradação, nas linhas 09 e 10), o que aponta, mais uma vez, para uma avaliação implícita, dependente de fatores contextuais, para o seu entendimento. Ter o circo armado significa existir baderna, bagunça, confusão, o que, mais uma vez, contextualiza e orienta as participantes da interação narrativa sobre a carga dramática do momento narrativo.

Na linha 13, Adriana N. se alinha à Carina e avalia a situação, de forma hipotética, como sendo culpa da narradora. Podemos entender a fala de Adriana N. como uma avaliação negativa voltada à mãe de Carina que, nesse momento, aparentemente demonstra estar a favor do irmão da mestranda - o que pode ser expresso na fala da narradora, ao se remeter ao "tom meio áspero" da voz de sua mãe (linha 12). Esse alinhamento de Adriana N. à Carina também é expresso pela interrupção do turno da narradora em "tipo assim" (linha 12), quando a professora infere que sua mãe a culparia pela briga com seu irmão.

Como o tema geral das narrativas contadas na interação do grupo de pesquisa era sobre violências sofridas por mulheres, e tendo como pano de fundo para discussão os textos sobre a Lei Maria da Penha, é possível nos remetermos a este contexto maior da reunião para entendermos a fala de Adriana N. No caso, a coordenadora constrói uma oposição ao padrão hegemônico deterministicamente atribuído às mulheres como as causadoras de confusões e, aos homens, como os que sofrem consequências das atitudes 
dessas mulheres. Notamos, assim, que as identidades de gênero são performadas e projetadas ao longo deste primeiro micro contexto interacional, quando há a construção colaborativa das avaliações dos fatos narrados.

Carina é a narradora principal, tendo domínio da maior parte dos turnos, inclusive, os mantêm discursivamente sobre o seu comando, conforme observaremos mais adiante. Contudo, ainda assim, percebemos que, de modo colaborativo, as participantes falam simultaneamente, por meio de sobreposições e de falas coladas, sobretudo, no excerto 2.

\section{Excerto 2}

14 Carina é (.) e eu falei assim "então fala para mim o que o que aconteceu o que 15 que você ouviu::” (...)

16 Adriana N. oéo

17 Carina e aí minha mãe [falou assim] "ahn (.) você precisa [ser mais CALma]

18 porque você é [muito isso"]

19 Monique [ahn::: é:::]

20 Adriana N. [Impressionan::te]=

21 Monique é a calça ver[de]

22 Adriana N. [é a] calça verde limão [sabe]

23 Monique

24 você é não sei o que

25 Adriana N. é:: exata[men::te

26 Carina "[você já] sabe que seu irmão é assim:::"

27 Adriana N. você já que seu irmão é::=

28 Todas $=(($ fala incompreensível $))$

29 Adriana N. seu irmão é machis::ta, é nervo::so

30 Carina olha só o que aconteceu foi o seguinte aconteceu isso, isso, isso, isso, >aí 31 eu contei toda a minha versão da história aí ele ficou olhando porque meu 32 irmão é assim extremamente cínico< sempre foi

33 Adriana N. seu irmão $\uparrow$

34 Monique Hhhh

35 Carina É::: desde que nós éramos pequenos

36 Aline otipo assim carinha de inocente ${ }^{\circ}=$

No segundo excerto, há a construção engajada e solidária da conversa, pois as falas estão se entrecruzando para formar significados locais mutuamente compreendidos por todas. $\mathrm{O}$ entendimento compartilhado e construído interacionalmente evidencia uma posição discursiva das participantes, que surge em oposição e em discordância à postura de homem que agride, seja de qualquer forma, uma mulher. 
Observamos que Carina abre o segundo fragmento fazendo uso de discursos reportados ${ }^{16}$, isto é, traz para o seu relato discursos que foram produzidos por ela e por sua mãe no mundo da história: "então fala para mim o que o que aconteceu o que que você ouviu::" (linhas 14 e 15) e "ahn (.) você precisa [ser mais CALMA] porque você é [muito isso"]", linhas 17 e 18. O entrecruzar do mundo da história com o mundo da narração confere alta carga dramática à narrativa e é visto, nesta pesquisa, como uma avaliação implícita que reproduz a hegemonia masculina e que projeta em Carina uma identidade de mulher nervosa, que precisa acalmar-se diante de um homem.

A narradora abre o trecho contando sua aparente busca pelo alinhamento de sua mãe (linhas 14 e 15), tentando saber o que ela ouviu de seu irmão, para, possivelmente, poder dar a sua própria visão da violência ocorrida. No entanto, sua mãe responde com uma avaliação negativa de seu comportamento, com o uso de um julgamento negativo de estima social, evidenciando a não normalidade do comportamento de sua filha (linhas 17 e 18). De forma contrária, a mãe de Carina parece normatizar o comportamento de seu filho, quando, na linha 26 , tem sua fala mais uma vez reportada pela narradora "você já sabe que seu irmão é assim". A fala reportada é repetida quase integralmente por Adriana N. no turno seguinte e que, na linha 29, completa o que seria "ser assim": "machista e nervoso".

O discurso da mãe, reportado na interação (linhas 17 e 18), causa estranhamento e resistência das outras participantes, que não concordam com o seu posicionamento, como visto na linha 20, quando Adriana $\mathrm{N}$. entende o fato como "impressionante", e no turno de Monique, nas linhas 23 e 24, quando diz "[é::::] você foi criar confusão::: você é não sei o que". As falas de ambas as interlocutoras são instâncias avaliativas negativas de julgamento de estima social, que podemos sugerir que voltam-se à capacidade de uma mulher, mãe de Carina, de agir desta maneira. Há, nas falas de Adriana N. e de Monique, indignação quanto à reprodução de ideologias de gênero, veiculadas por uma mulher, cujo discurso é carregado de princípios e valores determinados, indistintamente, a outra mulher em uma sociedade patriarcal.

Tal indignação é reforçada novamente com o retorno do tema de outra história (linhas 21 e 22), narrada no início da reunião por Adriana N. Em sua história, a coordenadora do grupo de pesquisa relata uma situação vivida com seu irmão mais velho, em sua juventude, quando este recusou-se a levá-la a uma festa pelo fato de ela estar usando uma calça da cor verde-limão, não aprovada pelo rapaz. Na ocasião, assim como a mãe de Carina, a mãe de Adriana N. alinhou-se ao filho e disse à filha que parasse de criar caso e que trocasse de roupa, caso realmente desejasse ir à festa. $\mathrm{O}$ evento gerou grande resistência da jovem na ocasião, que recusou-se a seguir as

16 O discurso reportado, utilizado com frequência nos dados deste estudo, é aqui entendido como "um recurso narrativo (...) usado para realçar aspectos importantes do mundo das histórias" (DE FINA, 2003, p. 93). De Fina considera que o discurso reportado tem uma função estratégica, sendo um processo ativo de transformação da fala do outro. A transferência pode se configurar de forma direta (quando o discurso é reportado em forma de diálogo) ou indireta (quando o discurso reportado é parafraseado). 
orientações de sua mãe, e sua história ficou marcada pelas participantes do grupo de pesquisa como um abuso moral sofrido por um homem.

Podemos dizer que o comportamento do irmão de Carina, bem como o comportamento do irmão de Adriana N., representam discursos ideológicos de poder, em que o homem é visto como aquele que pode agir deliberadamente em relação às mulheres, pois estas devem seguir suas orientações. Entretanto, percebemos nos dois fragmentos até agora analisados, assim como em Bucholtz (1990), que as mulheres são usuárias ativas da língua e agentes de reflexão, ainda que ocorra uma opressão a priori.

O que observamos na interação analisada é que tal reflexão é feita de forma conjunta, a partir do engajamento das interlocutoras para construir uma identidade negativa do irmão de Carina como "machista" e "nervoso" ("seu irmão é machis::ta, é nervo::so", linha 29). Ao mesmo tempo, de forma indireta, podemos inferir que também o irmão de Adriana N. pode ser considerado machista e nervoso, uma vez que a história sobre o uso da calça verde-limão é trazida em analogia à situação vivida por Carina. Nesse sentido, "calça verde-limão" passa a ser uma avaliação negativa explícita e evocada, altamente dependente do contexto interacional, e compartilhada pelas membras da reunião. Esta afirmação se torna ainda mais evidente quando notamos que a avaliação foi inicialmente feita por Monique, que se apropriou da história anterior para julgar o comportamento do irmão e da mãe de Carina. Deparamonos, assim, com a força da avaliação para a construção de sentidos, os quais, nesta análise, relacionam-se às (re)construções de identidades de gênero de Carina e das participantes da situação investigada.

Conforme comentamos anteriormente, propomos que houve um tipo de "catarse" com as experiências trazidas para o encontro, e isto se deu de forma colaborativa na (co)narração dos fatos, ilustrando que os eventos reportados (e seus participantes) são construídos no turno a turno da interação, entre as alunas e as professoras. Isto se faz claro com a presença de turnos colados (representados na transcrição por =) e de falas simultâneas (representadas por [ ]). A fala colada é, segundo Cameron (2010), frequentemente tomada como um marcador de cooperação, uma vez que, para realizá-la com precisão, é fundamental que o falante esteja muito atento à contribuição de outros atores sociais. Sendo assim, Carina não atua sozinha na construção de sua história, nem o faz quando avalia os eventos ocorridos, já que conta com a participação colaborativa das demais participantes do grupo - ainda que governe grande parte dos turnos, como veremos no excerto 3, abaixo. 


\section{Excerto 3}

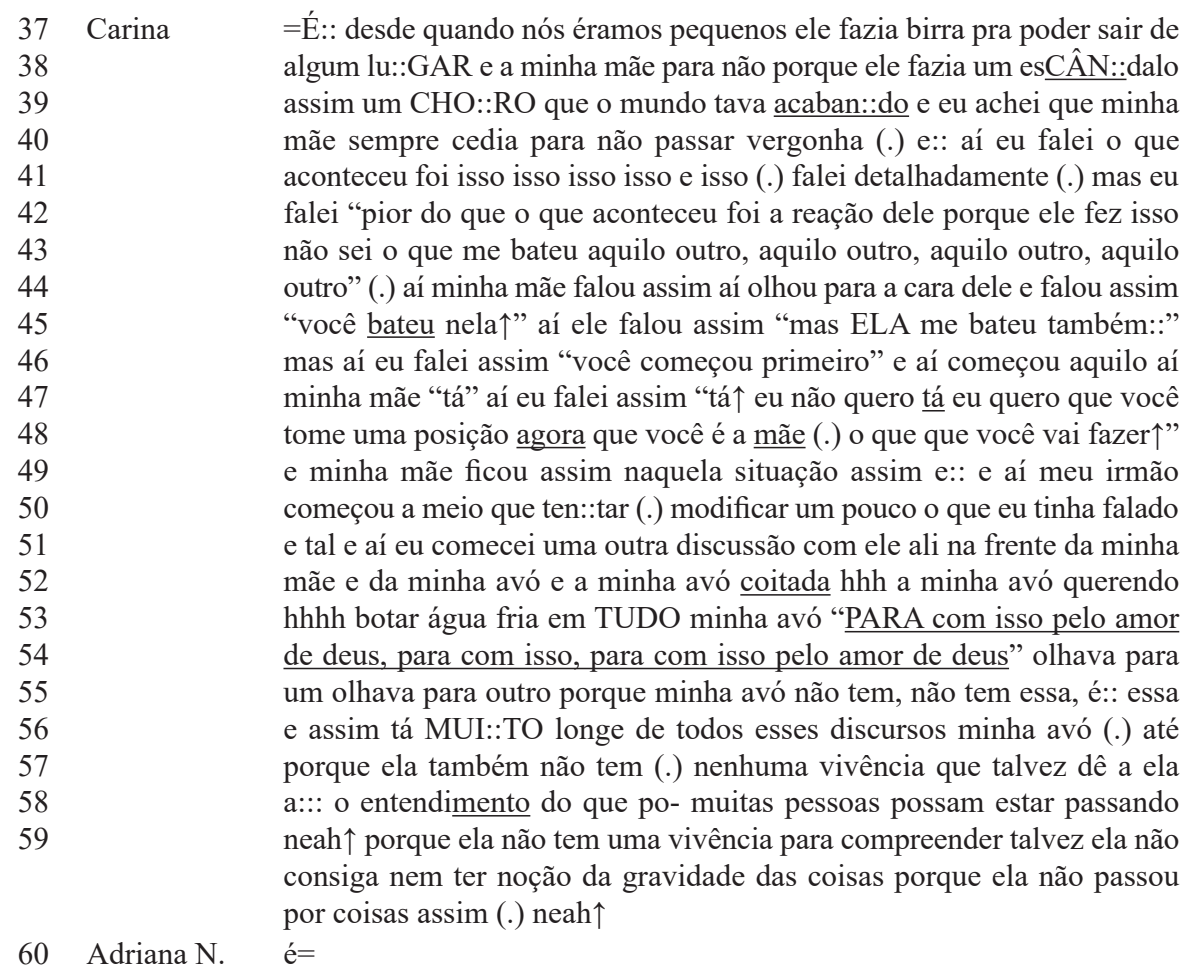

Carina continua se construindo identitariamente em oposição ao comportamento de seu irmão que sempre "fazia birra pra poder sair de algum lu::GAR" (linhas 37 e 38). Nesse caso, ela se posiciona como diferente do rapaz, configurando um sentimento de não pertencimento ao grupo dos que choram para conseguir alguma coisa (linhas 37-39). Observamos, desse modo, que a narradora parece não abrir sua fala narrativa para negociar o seu entendimento sobre a situação ocorrida, já que cria interpretações contundentes sobre o comportamento do irmão e da própria mãe, em um turno longo e sem interrupções. Tal aspecto denota a aprovação do restante do grupo, que adota uma postura mais colaborativa diante da interação, deixando espaço para que Carina (re)construa sua experiência sem ser interrompida. Observamos que Carina se constrói discursivamente como uma pessoa que tem uma atitude firme, é forte e corajosa, performando discursivamente essas identidades para si ao longo de toda a interação. Principalmente, e de nosso maior interesse, ela constrói suas identidades de gênero, o que também neste terceiro excerto é ilustrado pela escolha da narradora quando cobra, nas linhas 46-47, uma ação da mãe, que não deve aceitar passivamente o discurso de autoridade do filho, já que ele agiu brutalmente. Tal atitude ilustra como estamos cercados por ideologias masculinas de poder, que, na maioria dos casos, não são questionadas. A mãe aceita o comportamento do filho, mas logo é questionada por 
sua filha, que constrói sua identidade como mecanismo linguístico de autoproteção (BUCHOLTZ, 1990).

Apesar de manter uma postura contestadora, observamos que Carina também apresenta um discurso que apaga as ideologias patriarcais que sempre existiram na sociedade, não considerando a possibilidade de a mulher sempre ter tido um papel de submissa e, consequentemente, sempre ter sido oprimida por discursos machistas. Isso fica evidente quando ela afirma que sua avó não está alinhada aos discursos atuais (linhas 57-59), quando podemos afirmar que a opressão feminina existe desde sempre e se constitui como uma ferramenta para o estabelecimento do poder à classe dominante (mesmo que não conscientemente elaborada ou percebida).

Ressaltamos, por fim, que, neste terceiro excerto, a (re)construção das identidades de gênero da narradora é marcada por suas avaliações dos fatos, com forte dependência de elementos contextuais do mundo da narração (a reunião do grupo de pesquisa) e do mundo da história (o relato da agressão sofrida). Para podermos entender suas (re) construções de identidades de gênero, é preciso que tomemos por base o contexto sócio-histórico e situado de Carina e de sua família, assim como o ambiente da reunião do grupo de pesquisa.

\section{Excerto 4}

94 Monique
95
96
97
98
99
100
101
102
103
104
105
106
107
108
109
110
111
112

essa história Carina] e eu [estou lembrando=]

[você está contando [=não é não rapidinho deixa] eu só terminar (.) aí (.) aí a minha mãe ficou naquela situação começou a chorar coisa e tal e eu falei assim aí ela "mas o que que eu vou fazer $\uparrow$ " eu falei assim "se você não tomar uma posição EU vou envolver a família intei::ra nesse assunto (.) eu vou falar para os meus tios, eu vou falar com as minhas tias eu vou falar com todo mundo vou envolver a família toda nesse assunto e vou expor pra TODO mundo o que que aconteceu aqui em casa" (...) aí minha mãe ficou assim "meu deus" e aí meu irmão "isso é um problema NOSSO que tem que ser resolvido AQUI para que que você vai levar sua fofoqueira você vai levar isso para a família toda" aí eu fa- "não porque iss- isso pode estar acontecendo aqui, pode estar acontecendo na casa da minha tia também e pode estar não sei o que" e aí enfim eu só sei que aí minha mãe se viu assim meio que força- e aí eu joguei muitas coisas na cara dela aí eu falei assim "eu não estou te entenden::do (.) na verdade eu não estou nem te reconhecen::do porque você tem um discurso pra MIM em relação ao que está lá fora EU com aqueles que eu me relaciono você não tem que aceitar, você não-" eu nunca graças eu nunca passei por nenhuma situação assim vexatória com [ninguém]
113 Adriana N.
[hurrum]
114 Carina
115
com quem eu me relaciona::sse (.) "mas assim você não tem com os
116 outros mas como você está agindo com meu ir- não tô entendendo porque é seu filho $\uparrow "$ sabe (.)
117 Adriana N
É 
Neste último fragmento, notamos que Carina não cede o turno à Monique, que tenta iniciar, nas linhas 94 e 95, uma narrativa ("[você[=não é não rapidinho deixa] eu só terminar está contando essa história Carina] e eu [estou lembrando=]"), mas logo é interrompida pela colega ("[=não é não rapidinho deixa] eu só terminar", linhas 96 e 97). Percebemos, com isso, que Carina, envolvida com a sua própria história, não deixa a colega falar. Tais atitudes da participante tem correlação com a construção de sua performance identitária. Ela se (re)constrói identitariamente na dinâmica discursiva, que está em coerência com o conteúdo proposicional que ela apresenta e, consequentemente, em diálogo com as identidades por ela estabelecidas.

Assim como no excerto anterior, Carina não abre espaço para a negociação de sentidos e narra sua experiência de forma não modalizada, com alto grau de gradação nos fatos relatados, conferindo forte carga dramática (principalmente negativa) à narrativa. É o que acontece entre as linhas 99 e 102, quando ameaça contar a agressão para toda sua família, fazendo uso do atributo "inteira" com alongamento de vogal, o que ilustra uma avaliação. Contar para seus tios, suas tias e para "todo mundo" torna-se uma avaliação negativa com base no afeto de insatisfação e de infelicidade da narradora. Expor o fato para toda sua família é uma avaliação com alta gradação negativa da atitude de seu irmão e de sua mãe. Tal fato torna-se claro, também, com a resposta da mãe de Carina, quando diz "meu deus" (linha 103), em alusão à gravidade da ameaça da filha, e também, nas linhas 103 e 104, quando seu irmão, em tom de voz elevado, diz "isso é um problema nosso" e que deve ser resolvido "aqui”.

A aluna faz uso de um discurso reportado, trazendo a própria fala para o evento narrado, o que nos sugere como ela mantém a identidade de avaliadora, de alguém que cobra por justiça e que coloca em dúvida a própria identidade de uma mãe que criou uma filha para não ser submissa ao homem (linhas 108-111 e 114-116): “eu não estou te entenden::do (.) na verdade eu não estou nem te reconhecen::do porque você tem um discurso pra MIM em relação ao que está lá fora EU com aqueles que eu me relaciono você não tem que aceitar, você não-" (...) "mas assim você não tem com os outros mas como você está agindo com meu ir- não tô entendendo porque é seu filho ${ }^{\prime}$ " sabe (.)". Ao contestar a postura da mãe, Carina demonstra que não aceita que uma mãe deva sempre proteger o filho, já que, se o mesmo cometeu um ato impróprio, deve pagar por sua ação. Essa postura mais uma vez sugere que, apesar de haver uma opressão apriorística, as mulheres são usuárias ativas da língua (BUCHOLTZ, 1990) e, do mesmo modo, produtoras ativas de "comportamentos generificados (...) embutidos em modos específicos de falar e de agir a fim de produzir uma gama de efeitos" (CAMERON, 2010, p. 133).

Nos excertos até aqui analisados, vimos que Carina toma a palavra na maior parte da interação, quase não cedendo o turno e buscando mantê-lo sob o seu controle durante quase treze minutos, em meio a outras mulheres que também parecem ansiosas para contar suas histórias. Durante todo esse tempo, podemos notar uma multiplicidade de identidades sendo construídas e projetadas para o outro do evento narrado. Há uma performance narrativa de gênero e Carina se constrói como heroína, nos apresentando 
sua identidade de guerreira, corajosa, justiceira e independente. Ela se coloca em posição de avaliadora e de juíza dos outros, avaliando cada comportamento e dizendo o que está certo ou errado, no lugar daquele que pode promulgar uma sentença: "se você não tomar uma posição EU vou envolver a família intei::ra nesse assunto (.) eu vou falar para os meus tios, eu vou falar com as minhas tias eu vou falar com todo mundo vou envolver a família toda nesse assunto e vou expor pra TODO mundo o que que aconteceu aqui em casa" (linhas 99-102).

Podemos dizer, assim como Butler (2003), que temos uma multiplicidade de identidades sendo colaborativamente reconstruídas e projetadas, isto é, por um lado somos muitas coisas, ao mesmo tempo em que a cada evento discursivo performamos uma gama de identidades. Existe uma construção discursiva e múltipla de identidades, que estão em jogo no momento em que interagimos com o outro, como podemos perceber nos dados deste estudo.

\section{Considerações finais}

No presente estudo, analisamos a construção de identidades de gênero em narrativas de experiências pessoais, observando a interação entre sete participantes de um mesmo grupo de pesquisa e uma professora convidada, de outra instituição de ensino superior. Com o objetivo de investigar como as participantes estruturam, negociam e (re)constroem identidades ao longo das histórias contadas, encontramos o uso de sobreposições para a manutenção do engajamento narrativo e do tópico conversacional, pois em muitos casos as participantes se alinharam quando ilustraram uma recusa às normas patriarcais que governam o sistema social. Ainda que a participante Carina tenha controlado grande parte dos turnos, acreditamos que o uso das sobreposições e das falas coladas evidenciam o modo colaborativo e engajado da conversa, bem como contribuem para a organização sequencial da fala-em-interação.

Torna-se clara a importância da avaliação para a (re)construção colaborativa das identidades de gênero que foram performadas na interação investigada. Foi possível percebermos que ao avaliar (de forma explícita, mas, principalmente, de forma implícita) os eventos narrados por Carina, identidades foram construídas em oposição à agressão sofrida pela narradora, seja em relação ao comportamento de seu irmão ou ao de sua mãe e de sua avó. A observação dos elementos avaliativos, especialmente os em alta gradação, nos sugere a insatisfação e a infelicidade de Carina. Tanto o afeto como o julgamento de estima social (negativos) das participantes em relação ao comportamento do irmão da narradora, são fatores constitutivos na formação das identidades de Carina, de seus familiares e das participantes do grupo.

Também notamos o quanto o trabalho de narrar envolve aspectos socioculturais mais amplos, ao mesmo tempo em que é orientado por variações individuais de cada participante. A narradora principal, como dito anteriormente, se (re)constrói identitariamente como guerreira, corajosa, justiceira, juíza e independente, sempre em 
oposição ao outro. Seu irmão, por exemplo, é construído discursivamente como fraco, machista, chorão, fuxiqueiro e nervoso. Cabe ressaltar que os significados construídos nos eventos que são montados nessa narrativa resultam de uma situação interacional realizada no aqui e agora, sendo a narrativa co-produzida por interlocutoras situadas socio-historicamente. Além disso, as análises nos ilustram que o discurso reportado direto foi usado com frequência para estabelecer o envolvimento na narração, pois é visto como um recurso avaliativo que proporciona um maior envolvimento entre as membras do grupo de pesquisa. $\mathrm{O}$ ato de avaliar em narrativas é, portanto, um recurso significativo para o aumento da carga dramática da história relatada.

Esta pesquisa, então, a partir da abordagem crítica proposta pela Linguística Aplicada Contemporânea, buscou olhar para a avaliação na dinâmica interacional da narração, com vistas a observar como as participantes lidam com as questões de gênero presentes em uma sociedade patriarcal e heteronormativa. Por meio de princípios e de normas socioculturais e interacionais que regem as construções discursivas, nos foi possível observar como, muitas vezes, somos influenciadas por padrões que reforçamos por forças ideológicas maiores. Ainda assim, percebemos que houve uma contestação por parte da narradora principal, que se mostrou uma usuária ativa da língua e uma agente de reflexões.

Após concluir nossas análises e discussões, acreditamos que a perspectiva performativa de gênero aqui adotada ilustrou como é possível apontar alguns dos mecanismos pelos quais a estrutura patriarcal se instala e se consolida, dominando e determinando o sistema social. Percebemos que há uma violência de gênero, ainda impulsionada por uma ideologia patriarcal onde a mulher é inferior ao homem e deve ser sempre submissa a ele. Por fim, reiteramos, em alinhamento ao referencial teórico aqui utilizado, que tanto os gêneros como as identidades são produtos das performances locais de indivíduos socio-historicamente situados em atividades discursivas diversas.

NÓBREGA, A.; ABREU, A. Evaluation, identities and gender: analysis of domestic violence narratives in an interaction among women. Alfa, São Paulo, v.65, 2021.

- ABSTRACT: This research investigates the relationship between the evaluative uses of language and the (re)constructions of gender identities from the analysis of oral narratives about domestic violence, suffered by women in their family contexts, reported in an academic interaction. Grounded on the area of Contemporary Applied Linguistics, the theoretical and methodological framework followed a critical stance and the research analyzes how participants structure, negotiate and (re)construct their identities along the narratives, observing how they cope with gender issues, ideologically imposed by the society. Hence, to reach the above objectives, we propose an interface between the perspective of gender as a performative act, performed through the use of language, with the interactional approach of narrative and the socio-constructionist view of identities. The qualitative methodology oriented the analysis of the narrative practice, which was centered on the evaluative elements that 
constituted the narrative discourse. Results suggest that both gender and identities are products of local performances of sociohistorical individuals, situated in several discursive activities.

- KEYWORDS: oral narratives of personal experience; domestic violence; gender identities; evaluation.

\section{REFERÊNCIAS}

ABREU, A. R. Desafios do magistério: a coconstrução de identidades em microcenas narrativas de professores da Educação Básica. 2018. 193p. Tese (Doutorado em Letras) Pontifícia Universidade Católica, Rio de Janeiro, 2018.

ALBA-JUEZ, L.; THOMPSON, G. Introduction. In: THOMPSON, G.; ALBA-JUEZ, L. (ed.). Evaluation in context. Amsterdam: Philadelphia: John Benjamins, 2014. p. 3-26.

BASTOS, L. C. Diante do sofrimento do outro: narrativas de profissionais de saúde em reuniões de trabalho. Calidoscópio, São Leopoldo, v. 6, n. 2, p. 76-85, 2008.

BASTOS, L. C. Contando histórias em contextos espontâneos e institucionais: uma introdução ao estudo da narrativa. Calidoscópio, São Leopoldo, v. 3, n. 2, p. 74-87, 2005.

BASTOS, L. C. Narrativa e vida cotidiana. SCRIPTA, Belo Horizonte, v. 7, n. 14, p. 118-127, 2004.

BEAUVOIR, S. O segundo sexo: a experiência vivida. 2 ed. São Paulo: Divisão Europeia do Livro, 1967.

BORGES, T. R. S. Por um sentir crítico: um olhar feminista interseccional sobre a socioconstrução de identidades sociais de gênero, raça/etnia e classe de professoras de línguas. 2016. 232p. Dissertação (Mestrado em Letras) - Pontifícia Universidade Católica, Rio de Janeiro, 2016.

BRASIL. Presidência da República. Secretaria Geral Subchefia para Assuntos Jurídicos. Lei $\mathrm{n}^{\circ}$ 11.340, de 7 de agosto de 2006. Diário Oficial, Brasília, 2006. Disponível em: http://www.planalto.gov.br/ccivil_03/_Ato2004-2006/2006/Lei/ L11340.htm. Acesso em: 15 jan. 2021.

BUCHOLTZ, M. Bad examples: Transgression and Progress in Language and Gender Studies. In: BUCHOLTZ, M.; LIANG, A.C.; SUTTON, L.A. (ed.). Reinventing Identities: The Gendered Self in Discourse. New York: Oxford University Press, 1990. p. 3-26.

BUCHOLTZ, M.; HALL, K. Identity and Interaction: A Socio-cultural Linguistic Approach. Discourse Studies, New York, v, 7, n. 4/5, p. 585-614, 2005.

BUCHOLTZ, M.; HALL, K. Language and Identity. In: DURANTI, A. (ed.). A Companion to Linguistic Anthropology. Oxford: Basil Blackwell, 2003. p. 369- 394. 
BUTLER, J. Sexual politics, torture, and secular time. The British Journal of Sociology, London, v 59, n. 1, p.1-23, 2008.

BUTLER, J. Problemas de gênero: feminismo e subversão da identidade. Rio de Janeiro: Civilização Brasileira, 2003.

BUTLER, J. Gender trouble: feminism and the subversion of identity. London: New York: Routledge; Chapman \& Hall, 1990.

CAMERON, D. Desempenhando identidade de gênero: conversa entre rapazes e construção da masculinidade heterossexual. In: OSTERMAN, A.C.; FONTANA, B. (org.). Linguagem, gênero e sexualidade. São Paulo: Parábola, 2010. p. 129-149. (Clássicos traduzidos).

CAMERON, D. Working with Spoken Discourse. London: Sage, 2001.

DE FINA, A. Who tells which story and why? Micro and macro contexts in narrative. Text \& Talk, Germany, v. 28, n. 3, p. 421-442, 2008.

DE FINA, A. Identity in narrative: a study of immigrant discourse. Amsterdam: John Benjamins, 2003.

DE FINA, A.; GEORGAKOPOULOU, A. Introduction: Narrative analysis in the shift from texts to practices. Text \& Talk, Germany, v. 28, n. 3, p. 275-281, 2008.

DENZIN, N. K.; LINCOLN, Y. (org.). O planejamento da pesquisa qualitativa: teorias e abordagens. 2. ed. Porto Alegre: Artmed, 2006.

EGGINS, S. An Introduction to Systemic Functional Linguistics. London: Continuum, 2004.

FAIRCLOUGH, N. Analysing Discourse: textual analysis for social research. London: Routledge, 2003.

FOUCALT, M. A História da Sexualidade: a vontade de saber. Rio de Janeiro: Graal, 1977. v.1.

GOFFMAN, E. A representação do eu na vida cotidiana. 20. ed. Petrópolis: Rio de Janeiro: Vozes, 2014. Original de 1959.

GOUVEIA, C. A. M. Texto e gramática: uma introdução à linguística sistêmicofuncional. Matraga, Rio de Janeiro, v. 24, p. 13-47, 2009.

HALLIDAY, M. A. K. An Introduction to Functional Grammar. London: Arnold, 1994.

HAllidAY, M. A. K.; HASAN, R. Language, Context, and Text: Aspects of Language in a Social-semiotic Perspective. Oxford: Oxford University Press, 1989.

HALLIDAY, M. A. K.; MATTHIESSEN, C. Halliday's Introduction to Functional Grammar. London: Routledge, 2014. 
LABOV, W. The transformation of experience in narrative syntax. In: LABOV, W. Language in the inner city. Philadelphia: University of Pennsylvania Press, 1972. p. 354-396.

LABOV, W.; WALETZKY, J. Narrative analysis: oral versions of personal experience. In: HELM, J. Essays on the verbal and visual arts. Seattle: University of Washington Press, 1967. p. 12-44.

LINDE, C. Evaluation as linguistic structure and social practice. In: GUNNARSSON, B.L.; LinElL, P.; NORDBERG, B. (ed.). The Construction of Professional Discourse. London: Longman, 1997. p. 151-172.

LODER, L. L.; JUNG, N. M. Análises de fala-em-interação institucional: a perspectiva da Análise da Conversa Etnometodológica. Campinas: Mercado de Letras, 2009.

MACKEN-HORARIK, M; ISAAC, A. Appraising appraisal. In: THOMPSON, G.; ALBA-JUEZ, L. (ed.). Evaluation in context. Amsterdam: Philadelphia: John Benjamins, 2014. p. 67-92.

MARTIN, J. Beyond Exchange: Appraisal systems in English. In: HUSTON, S.; THOMPSON, G. (ed.). Evaluation in Text: Authorial Stance and the Construction of Discourse. Oxford: Oxford University Press, 2001. p.142-175.

MARTIN, J. R.; ROSE, D. Working with discourse: meaning beyond the clause. 2. ed. New York: Continuum, 2007.

MARTIN, J.; WHITE, P. The Language of Evaluation: Appraisal in English. New York: Palgrave; Macmillan, 2005.

MEAD, M. Sexo e temperamento em três sociedades primitivas. 5. ed. São Paulo: Perspectiva, 1979.

MOITA LOPES, L. P. Lingüística Aplicada e vida contemporânea: problematização dos construtos que têm orientado a pesquisa. In: MOITA LOPES, L. P. (org.). Por uma Lingüística Aplicada Indisciplinar. São Paulo: Parábola, 2006. p. 85-107.

MOITA LOPES, L.P. Socioconstrucionismo: discurso e identidades sociais. In: MOITA LOPES, L.P. (ed.). Discurso de identidades. Campinas: Mercado de Letras, 2003. p. $13-38$.

MOITA LOPES, L.P. Identidades fragmentadas: a construção de raça, gênero e sexualidade na sala de aula. Campinas: Mercado de Letras, 2002.

MOITA LOPES, L. P. Práticas narrativas como espaço de construção das identidades sociais: uma abordagem socioconstrucionista. In: RIBEIRO. B.T; LIMA, C. C.; DANTAS, M. T. (org.). Narrativa, identidade e clínica. Rio de Janeiro: Edições IPUB, 2001. p. 56-71. 
NÓBREGA, A. N. Narrativas e avaliação no processo de construção do conhecimento pedagógico: abordagem sociocultural e sociossemiótica. 2009. 244p. Tese (Doutorado em Letras) - Pontifícia Universidade Católica, Rio de Janeiro, 2009.

NÓBREGA, A.N.; MAGALHÃES, C.E.A. Narrativa e identidade: Contribuições da avaliação no processo de (re-)construção identitária em sala de aula universitária. Veredas, Juiz de Fora, v. 16, n. 2. p. 68-84, 2012.

PENNYCOOK, A. Uma Lingüística Aplicada transgressiva. In: MOITA LOPES, L. P. (org.). Por uma Lingüística Aplicada indisciplinar. São Paulo: Parábola, 2006. p. $67-84$.

PENNYCOOK, A. Performativity, and language studies. Critical Inquiry in Language Studies: An International Journal, London, v. 1, p. 1-19, 2004.

REISSMANN, C. Narrative Analysis. Newbury Park: Sage, 1993.

RESENDE, V.; RAMALHO, V. Análise do discurso crítica. 2. ed. São Paulo: Contexto, 2006.

SACKS, H.; SCHEGLOFF, E.; JEFFERSON, G. A Simplest Systematics for the Organization of Turn Taking in Conversation. Language, Washington, v. 50, p. 696735, 1974.

SAWIM, P. E. Gender, Context, and the Narrative Construction of Identity. In: BUCHOLTZ, M.; LIANG, A.C.; SUTTON, L.A. (ed.). Reinventing Identities: The Gendered Self in Discourse. New York: Oxford University Press, 1990. p. 241-257.

THOMPSON, G; HUNSTON, S. Evaluation in text. In: BROWN, K. (ed.). The Encyclopedia of Language and Linguistics. Oxford: Elsevier, 2006. v. 4. p. 305-312.

THOMPSON, G; HUNSTON, S. Evaluation: an introduction. In: HUSTON, S.; THOMPSON, G. (ed.). Evaluation in Text: Authorial Stance and the Construction of Discourse. Oxford: Oxford University Press, 2000. p. 1-26.

VIAN JR., O. O Sistema de Avaliatividade e a linguagem da avaliação. In: VIAN JR, O.; SOUZA, A.; ALMEIDA, F. (ed.). A linguagem da avaliação em língua portuguesa: estudos sistêmico-funcionais com base no Sistema de Avaliatividade. São Carlos: Pedro \& João Editores, 2010. p. 19-29.

WHITE, P. The Appraisal website. Disponível em: www.grammatics.com/appraisal. Acesso em: 18 out. 2021.

WODAK, R. Do que trata a ACD: um resumo de sua história, conceitos importantes e seus desenvolvimentos. Linguagem em (Dis)curso, Palhoça, v. 4, n. esp, p. 223-243, 2004. 
ANEXO

Convenções de Transcriçãa ${ }^{17}$

\begin{tabular}{|c|c|c|c|}
\hline \multicolumn{4}{|c|}{ Aspectos da produção da fala } \\
\hline . & Entonação descendente & $\uparrow$ & $\begin{array}{l}\text { Som mais agudo do } \\
\text { que os do entorno }\end{array}$ \\
\hline$?$ & Entonação ascendente & $\downarrow$ & $\begin{array}{l}\text { Som mais grave do } \\
\text { que os do entorno }\end{array}$ \\
\hline , & $\begin{array}{l}\text { Entonação } \\
\text { intermediária, de } \\
\text { continuidade }\end{array}$ & $\mathrm{Hh}$ & Aspiração ou riso \\
\hline- & Parada súbita &.$h h$ & Inspiração audível \\
\hline$\underline{\text { Sublinhado }}$ & Enfase em som & opalavra ${ }^{\circ}$ & Fala em voz baixa \\
\hline MAIÚSCULA & $\begin{array}{l}\text { Fala em voz alta } \\
\text { ou muita ênfase }\end{array}$ & $>$ palavra $<$ & Fala mais rápida \\
\hline : ou $::$ & Alongamentos & $<$ palavra $>$ & Fala mais lenta \\
\hline [] & Fala sobreposta & \multicolumn{2}{|c|}{ Formatação, comentários, dúvidas } \\
\hline \multicolumn{2}{|r|}{ Tempo } & $=$ & $\begin{array}{c}\text { Elocuções contíguas, } \\
\text { enunciadas sem } \\
\text { pausa entre elas }\end{array}$ \\
\hline$\ldots$ & Pausa não medida & ( ) & Fala não compreendida \\
\hline$(2.3)$ & Pausa medida & (palavra) & Fala duvidosa \\
\hline (.) & $\begin{array}{l}\text { Pausa de menos de } 2 \\
\text { décimos de segundo }\end{array}$ & $(())$ & $\begin{array}{l}\text { Comentário do } \\
\text { analista, descrição de } \\
\text { atividade não vocal }\end{array}$ \\
\hline \multicolumn{4}{|c|}{ Outros } \\
\hline & palavra" & & relatada \\
\hline
\end{tabular}

Recebido em 3 de dezembro de 2019

Aprovado em 3 de julho de 2020

17 Convenções adaptadas de estudos da Análise da Conversação (SACKS; SCHEGLOFF; JEFFERSON, 1974), com incorporações de Loder e Jung (2009). 